\title{
Quantifying the effects of delisting wolves after the first state began lethal management
}

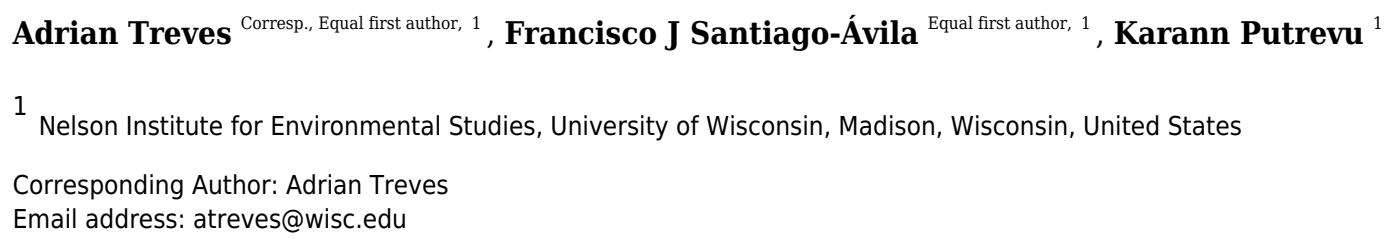

Predators and their protection are controversial worldwide. Gray wolves, Canis lupus, lost U.S. federal protection (delisting) on 3 November 2020 and the State of Wisconsin began lethal management first among all states and tribes that regained authority over wolves. Here we evaluated the initial success of reaching the state's explicit objective, “...to allow for a sustainable harvest that neither increases nor decreases the state's wolf population..." We used official state figures for hunter-killed wolves and population estimates from April 2017-April 2020 and the latest peer-reviewed model of individual wolf survival to estimate additional deaths resulting from federal delisting. More than half of the additional deaths were predicted to be cryptic poaching under the assumption that this period resembled past periods of liberalized wolf-killing in Wisconsin. We used a precautionary approach to construct three conservative scenarios to predict the current status of this wolf population and a minimum estimate of population decline since April 2020. From our scenarios that vary in growth rates and additional mortality estimates, we expect a maximum of 695-751 wolves to be alive in Wisconsin by 15 April 2021, a minimum $27-33 \%$ decline in the last 12 months. This contradicts the state expectation of no change in the population size. We draw a conclusion about the adequacy of regulatory mechanisms under state control of wolves and discuss the particular governance conditions met in Wisconsin. We recommend greater rigor and independent review of the science used by agencies to plan wolf hunting quotas and methods. We recommend clearer division of duties between state wildlife agencies, legislatures, and courts. We recommend federal governments reconsider the practice of sudden deregulation of wolf management and instead recommend they consider protecting predators as non-game or transition more slowly to subnational authority, to avoid the need for emergency relisting. 


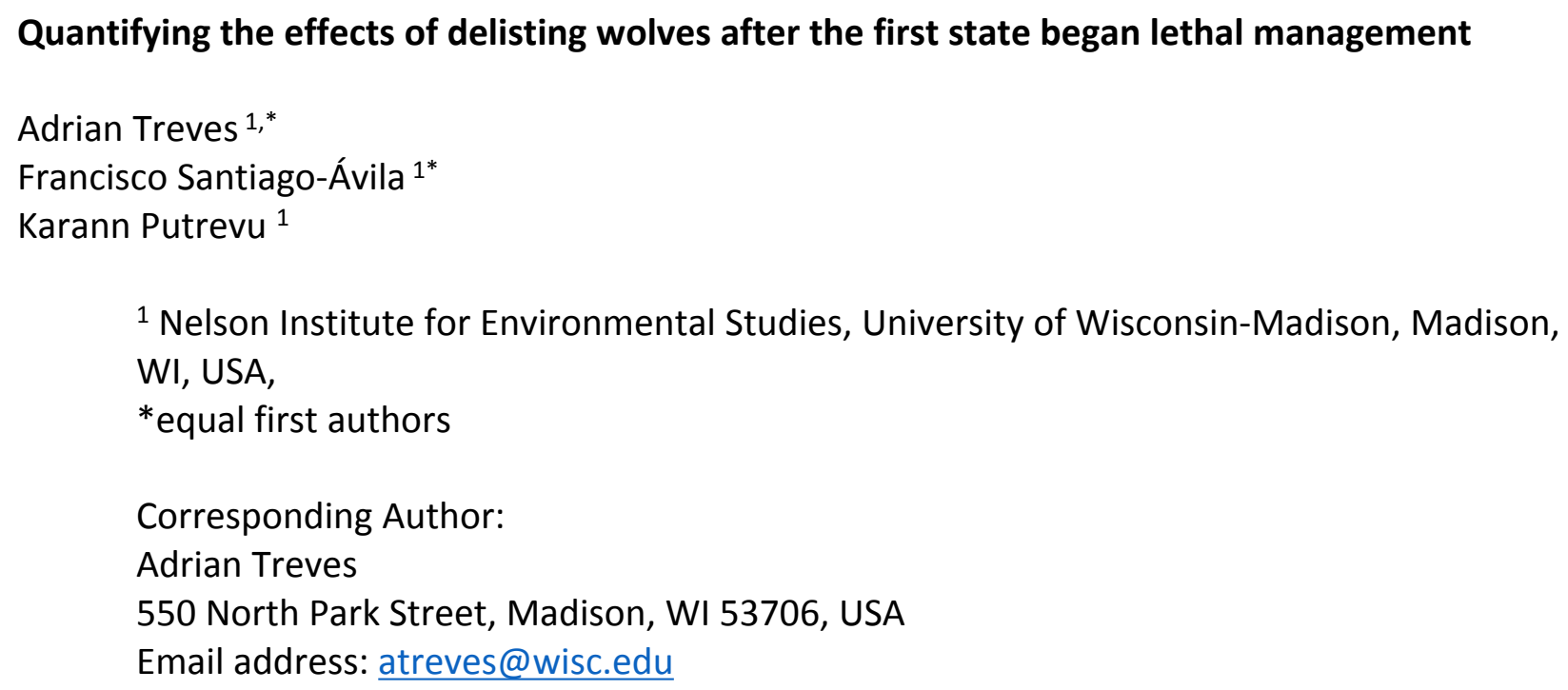

\section{Abstract}

Predators and their protection are controversial worldwide. Gray wolves, Canis lupus, lost U.S. federal protection (delisting) on 3 November 2020 and the State of Wisconsin began lethal management first among all states and tribes that regained authority over wolves. Here we evaluated the initial success of reaching the state's explicit objective, "...to allow for a sustainable harvest that neither increases nor decreases the state's wolf population..." We used official state figures for hunter-killed wolves and population estimates from April 2017-April 2020 and the latest peer-reviewed model of individual wolf survival to estimate additional deaths resulting from federal delisting. More than half of the additional deaths were predicted to be cryptic poaching under the assumption that this period resembled past periods of liberalized wolf-killing in Wisconsin. We used a precautionary approach to construct three conservative scenarios to predict the current status of this wolf population and a minimum estimate of population decline since April 2020. From our scenarios that vary in growth rates and additional mortality estimates, we expect a maximum of 695-751 wolves to be alive in Wisconsin by 15 April 2021, a minimum 27-33\% decline in the last 12 months. This contradicts the state expectation of no change in the population size. We draw a conclusion about the adequacy of regulatory mechanisms under state control of wolves and discuss the particular governance conditions met in Wisconsin. We recommend greater rigor and independent review of the science used by agencies to plan wolf hunting quotas and methods. We recommend clearer division of duties between state wildlife agencies, legislatures, and courts. We recommend federal governments reconsider the practice of sudden deregulation of wolf management and instead recommend they consider protecting predators as non-game or transition more slowly to subnational authority, to avoid the need for emergency relisting.

\section{Introduction}

Wolves and their protection are controversial worldwide and across the U.S. [1-6]. The U.S. Endangered Species Act (ESA) aims to remove listed species (delist) from federal protection once recovered but contingent on adequate regulations in subnational jurisdictions to keep them off the federal list. Two U.S. Presidential Administrations have proposed the removal of 
federal protections for gray wolves (Canis lupus) nationwide but faced dissent by majorities (if not unanimity) of their official panels of scientists [7, 8]. The Trump administration went ahead anyway and transferred authority to states and tribes on 3 November 2020, declaring gray wolves recovered across most of the country under the Endangered Species Act, ESA [9]. That decision asserts that the species met the criteria of the five-factor analysis (ESA 16 USC $\S 1531$ Sec. 4(a)) among others. The five factors necessary for delisting altogether ensure the delisted species remains secure for the foreseeable future. One of those criteria is the adequacy of state and tribal (subnational) regulatory mechanisms $[10,11]$.

Whether delisted wolves are being managed with adequate regulatory mechanisms by subnational jurisdictions seems in part a scientific question (as opposed to a values-based question), because the adequacy of the mechanisms depends on their effectiveness in regulating factors that might reverse conditions and endanger wolves again. Chief among those factors for wolves has been human-caused mortality in five U.S. wolf populations, since modern monitoring [12], as in other regions [5, 13]. We present a data point to support scientific evaluations of the adequacy of regulatory mechanisms in subnational jurisdictions, for the first state to implement recreational hunting in the wake of federal wolf delisting on 3 November 2020.

The State of Wisconsin wolf policy and management betweenn 2020-2021 offers an interesting case study for the following reasons. Wisconsin was the first subnational jurisdiction to resume lethal management of wolves after delisting. The State wildlife agency (Department of Natural resources, DNR) was explicit about its goals for regulated wolf-hunting, "The quota's objective is to allow for a sustainable harvest that neither increases nor decreases the state's wolf population..." (https://dnr.wisconsin.gov/topic/hunt/wolf/index.html accessed 14 April 2021) and similar statements to media before the wolf-hunt [14]. There are two phrases and two parts of that objective that can be evaluated scientifically, that of "a sustainable harvest" and "neither increases nor decreases the state's wolf population". This language mirrors recent reviews of the topic that have estimated the average expected, threshold rate of human-caused mortality predicted to result in stability of wolf populations (i.e., no increase or decrease).

The estimates of stabilizing levels of human-induced mortality that would be sustainable ranges from $28-29 \%$ [15] to 5-10\% lower estimates by [16-18]. A higher estimate by [19] has been questioned because of seeming errors in calculations [18], so their higher estimate needs replication or correction. We use this meaning of sustainability not the other meaning of sustain suggesting a wolf population can withstand one or two years of higher rates of mortality before extirpation. Our justification apart from the literature comes from the Wisconsin DNR itself, using the Adams et al. [15] estimate in prior wolf-hunting plans [20, 21], citation of those quota plans in 2021 [22], and explicit mention of using a 24\% threshold on 15 February 2021 [23] by $D$. MacFarland. Evaluating sustainability of natural resource uses demands long-term data, so here we only discuss the one-year outcome in light of the objectives. Nevertheless, we can evaluate the state objective scientifically because we have official hunt statistics official population estimates, and relevant, peer-reviewed scientific models. Namely, the wolves of Wisconsin were subject to two recent modeling efforts. First, models of population growth 
89

90

91

92

93

94

95

96

97

98

99

100

101

102

103

104

105

106

107

108

109

110

111

112

113

114

115

116

117

118

119

120

121

122

123

124

125

126

127

128

129

130

131

132

were built that took into account loosening of ESA protections as seen on 3 November 2020 [24-27]; note we use 3 November from the Federal Register for consistency with prior studies $[24,28]$. Also, individual survival models used time-to-event analyses to estimate cryptic poaching in competing risk frameworks [28]. These allow us to estimate population change in a single year and increments in human-induced mortality following delisting and through the wolf-hunt period. The serendipitous combination of population estimates, hunter-killed totals, and models of the individual and population-level effects of reducing ESA protections make this case unique to our knowledge.

Another feature of the Wisconsin case that makes it relevant beyond that State are the subnational governance issues involved. The DNR was not alone in deciding or designing the state wolf hunt. A local court, the legislature, and the Natural Resource Board (NRB), which is a commission overseen by both the executive and the legislature all had a say in the February 2021 wolf-hunt timing, methods, and quota (Supplementary Material 1). Therefore, the Wisconsin case study may provide readers from other regions with insights into the checks and balances across three independent branches of a democratic government.

Here we evaluate whether the state attained its objective "...to allow for a sustainable harvest that neither increases nor decreases the state's wolf population...", by modeling population change after the State of Wisconsin issued 2380 permits, intending to kill 119 wolves (https://dnr.wisconsin.gov/newsroom/release/41071, accessed 24 March 2021), but resulting in permitted kills of 218 wolves in $<3$ days [29].

\section{Materials and Methods}

We used official population estimates since April 2017 as the population grew from 925-1034 minimum counts (SM1) to estimate the population in April 2021. We began with population estimates and dynamics since April 2017, which represents the most recent 4 years of wolf population growth after the last wolf-hunt in December 2015 [30]. Therefore, we assume similar population dynamics, such as density-dependence, as observed in 2017-2020. We also assume the effects of that prior wolf-hunt had worked themselves out of the population dynamics preceding the wolf-hunt of February 2021. Some readers may be interested in seeing a one-year population change model that allows for density-dependence or compensatory effects on mortality, reproduction, recruitment, or migration. In SM2, we explain why a population model without such non-linear effects is the more conservative model.

We used three conservative scenarios for estimating population change. Our precautionary approach is to begin with the minimum bound of the April 2020 estimate by the State in its wolf population census. Our approach is precautionary because loners and transients contribute little to population growth or the total size of the population and few if any packs have been missed in previous years. Also, the minimum count of 1034 wolves in 256 packs is consistent with long-term average pack sizes around 4 wolves [31].

The first scenario, which we label $\mathrm{HIGH}$, uses the average growth estimated by the state during periods of strict ESA protection 2017-2020 $\left(\mathrm{N}_{\mathrm{t}+1}-\mathrm{N}_{\mathrm{t}}\right) / \mathrm{N}_{\mathrm{t}}=+3.8 \%$, and accounts for mortality 
133 additional to background levels found during those years to account for the delisting period 134 from 3 November 2020 to 14 April 2021. Specifically, we deduct additional deaths expected 135 during periods without ESA protection from a recent peer-reviewed model of individual survival 136 as policies changed.

137

138

139

140

141

142

143

144

145

146

147

148

149

150

151

152

153

154

155

156

157

158

159

160

161

162

163

164

165

166

167

168

169

170

171

172

173

174

175

Recent quantitative models predict that cryptic poaching - illegal killing in which perpetrators conceal evidence [32] - rises significantly for endangered wolves when wolf-killing or removal from the wild, mostly by government agents, is legally permitted [28, 33]. The latter two recent models used independent datasets to estimate mortality and disappearance of marked wolves from the date of collaring (mainly VHF radio transmitters) until death or disappearance, using individual-level, time-to-event analyses to compare periods of strict ESA protection to periods of reduced protection during which time wolf-killing or removal of wild wolves to captivity was liberalized [28, 33]. The rationale for assigning most disappearances of radio-collared wolves to cryptic poaching follows discussions in those papers and others [12, 34, 35], which we summarized in SM2 after describing depensatory mortality. The latter works improved upon earlier efforts [36, 37], as did [38], but those we use here also improved by explicitly accounting for radio-collared wolves that disappeared as a function of the length of time wolves were exposed to policy periods that reduced ESA protections [28]. Unregulated and often undocumented illegal killing (poaching) exceeded legal, reported wolf-killing in every population studied thus far $[12,15,32,34]$. Therefore, it is essential to accurate monitoring and quota-setting that prudent managers consider these additional deaths and count all mortality, or at least all anthropogenic mortality, when planning and communicating public hunting seasons.

The second scenario, which we label MODERATE, uses the minimum growth estimated by the state in those years $\left(\mathrm{N}_{\mathrm{t}+1}-\mathrm{N}_{\mathrm{t}}\right) / \mathrm{N}_{\mathrm{t}}=-2.2 \%$. Using the minimum population growth observed in the past 4 years is consistent with a precautionary approach and the findings for a population-level model of all wolves in Wisconsin and a model for Michigan from 1995-2012 [24, 25]. Those studies report that periods of liberalized wolf-killing were associated with an unidentified and unreported source of mortality that slowed population growth, independent of legal killing, by $4-6 \%$ annually. These studies resisted quantitative and qualitative challenges without published support for alternative hypotheses of density-dependence on mortality [26, 27, 39-41]. Furthermore, social scientific data corroborated the population-level findings with independent datasets $[42,43]$ and the authors' own findings $[44,45]$. This scenario also deducted additional wolf deaths as in the HIGH scenario.

Finally, for the third, LOW, scenario we took the minimum population growth observed in years of full ESA protection $(-2.2 \%)$ and subtract another $5 \%$, for a final decrement of $-7.2 \%$. The LOW scenario, LOW adjusts the observed minimum growth downward by $5 \%\left(\mathrm{~N}_{\mathrm{t}+1}-\mathrm{N}_{\mathrm{t}}\right) / \mathrm{N}_{\mathrm{t}}=-7.2 \%$, but does not add the additional mortality because that might double-count the effect of reduced protections after delisting on 3 November 2020.

Assumptions

PeerJ reviewing PDF | (2021:03:59550:1:1:NEW 28 Apr 2021) 
176 Our estimates contain a set of assumptions, all of which we aimed to make conservatively, so

177

178

179

180

181

182

183

184

185

186

187

188

189

190

191

192

193

194

195

196

197

198

199

200

201

202

203

204

205

206

207

208

209

210

211

212

213

214

215

216

217

218

219

our outputs are minimum estimates of deaths and maximum estimates of population size.

We report only the increment in deaths and disappearances after delisting, i.e., those that we estimate would have survived had delisting not proceeded. We use these as increments in mortality for the HIGH and MODERATE scenarios only. The lower estimate for additional deaths and disappearances comes from wolves in Wisconsin from 1980-2012 [28]. The higher estimate for Mexican gray wolves, in New Mexico and Arizona, is more certain because of more intensive monitoring of a greater proportion of the population [33]. Therefore, the Wisconsin estimates are conservative among available estimates of cryptic poaching increments.

As summarized in SM2, when we estimate additional wolf deaths and disappearances after delisting, we assume those wolves are lost to the Wisconsin population. Studies in at least four populations found that the vast majority of radio-collared wolf disappearances are earlier than would be expected from battery or mechanical failure [12, 28, 32-35]. We are aware of no evidence of a mechanism by which mechanical failure rates would increase in association with a liberalized killing period. Further, the Scandinavian studies that first described cryptic poaching used genetics to confirm the disappearance of known wolves, and later associated those rates to policies, concluded that missing wolves no longer moved on the landscape, as opposed to eluding monitoring [32, 46] but see our qualms about their inferences about policy effects [47]. Indeed, migration into rather than out of regions that experienced high rates of legal and illegal wolf-killing seems more likely. In the Alaskan gray wolf study widely used to identify a sustainability threshold for wolf-killing [15], the authors reported $>75 \%$ of human-caused mortality was caused by intentional, unregulated hunting, and that the off-take was unsustainable without large amounts of immigration.

Also, we assumed no super-additive mortality per capita of legal kills, as reported or inferred for exploited wolf populations $[17,18]$, because we assume our estimates of cryptic poaching model some super-additivity. This is conservative because failed pregnancies, litter loss, and unreported deaths of uncollared wolves that might accompany and follow the hunting and poaching would not have been captured in the individual models that used marked adult wolves only. Non-radio-collared wolves succumbed to all deaths at higher rates than radiocollared wolves in Alaska [48], and in Wisconsin [35]. Possibly some poachers are deterred by the threat of prosecution if they kill a collared animal [49]. In sum, estimates of incremental deaths and disappearances in the HIGH and MODERATE scenarios are likely to under-estimate deaths.

Next we assumed permitted wolf-killing will have similar effects on the wolf population and on would-be wolf-poachers as that estimated from 2003-2012, during which time government agents were primarily responsible for wolf-killing and no public hunts were held. This is conservative given the 2021 wolf-hunt killed more wolves than in past periods [24, 30], and did so with unprecedented methods (e.g., snowmobile chase, night-time, hounds, traps) in a very rapid timeframe. It would be plausible to assume rapid, efficient poaching also but we do not.

PeerJ reviewing PDF | (2021:03:59550:1:1:NEW 28 Apr 2021) 
220

221

222

223

224

225

226

227

228

229

230

231

232

233

234

235

236

237

238

239

240

241

242

243

244

245

246

247

248

249

250

251

252

253

254

255

256

257

258

259

260

261

262

263

Also, we assume all growth occurs prior to delisting because pups recruited into the population in November are treated as adults for purposes of census [50]. Relatedly, we assume that wolves alive on 15 April 2020 began their exposure to hazards at that time, rather than considering their full time alive as adults, for which we have no data. This is conservative because (1) the cumulative incidence (rather than the instantaneous hazard) of mortality increases with monitoring time naturally, and (2) the difference between the cumulative incidence functions for each protection period (Fig 1) increases with monitoring time beyond our study period $(t=365)$ [28].

Finally, we did not use unpublished, preliminary, unverified estimates provided by the DNR in April 2021 that 17 out of 50 collared wolves disappeared prior to or during the 2021 wolf-hunt and another 7 were killed by hunters (SM 1 Fig 1). Had we uncritically used those figures for deaths and disappearances of the entire wolf population, our estimate of wolf survival would have been $48 \%$ and the associated wolf population decline would have been much greater. But those data are unverified currently and as noted above collared wolves suffer different mortality hazard than uncollared ones in Wisconsin and elsewhere.

The formula we use for all three scenarios is

Eq. $1 \mathrm{~N}_{2021}=\left(\mathrm{N}_{2020} \bullet \mathrm{r}\right)-218-\mathrm{E}$

where $\mathrm{N}_{2020}=1034, \mathrm{r}$ varies by scenario as +0.038 (HIGH), -0.022 (MODERATE), or - .072 (LOW) respectively, and ' $E$ ' refers to additional wolves dead due to reduced ESA protections, calculated using the cumulative incidence functions (CIFs, Fig 1A,B) for all endpoints during a period of liberalized wolf-killing from [28] but set to zero for the LOW scenario. CIFs by policy periods for all endpoints and LTF (Fig 1A,B) were calculated using semi-parametric Fine-Gray models, with data from 513 monitored, adult wolves (1979-2012) [28].

We also estimate the proportion of all additional mortalities due to cryptic poaching, using the difference in CIFs for raio-collared wolves lost to follow-up. In the two types of policy periods (Fig 1B), divided by the same difference in the CIFs of all endpoints (Fig 1A) at day 365 (15 Apr 2021).

We do not attempt to model population change from 15 April 2021-November 2021 when the next wolf-hunt is putatively planned because there are too many uncertainties about reproduction, legality, and planning processes. A lack of transparency about state wolf data from 2013-2015 prevents independent scientific scrutiny of past regulated hunting $[28,51]$.

\section{Results}

We predict the state population by 15 April 2021 will stand at a maximum possible number of wolves of 695-751 wolves (scenarios: LOW 742, MODERATE 695, HIGH 751) (Tables 1, 2). This represents a minimum of a $27-33 \%$ decrease in one year. We emphasize that is a minimum and the population size is a maximum because of the many conservative methods we used.

Table 1 here 
264

265

266

267

268

269

270

271

272

273

274

275

276

277

278

279

280

281

282

283

284

285

286

287

288

289

290

291

292

293

294

295

296

297

298

299

300

301

302

303

Table 2 here

We estimate that in addition to the 218 wolves reported killed during the wolf-hunt, 98-105 wolves died since 3 November 2020 that would have been alive had delisting not occurred. Of these $56-63 \%$ (55-58 wolves) at a minimum would have been killed through cryptic poaching. Therefore, the addition of cryptic poaching and wolf-hunting in Wisconsin after 3 November 2020 seems to have augmented human-caused mortality by approximately $30 \%$ (320 of 10341071) over pre-delisting levels.

Figure 1 here

\section{Discussion}

We report the expected additional wolf mortality and population reduction in the aftermath of U.S. federal removal of endangered species protections followed by one state's swift adoption of a policy for liberalized wolf-killing, including permitted, public hunting, trapping, hounding, and snow-mobile pursuit by day and night. We estimate the incremental addition of at least 98105 wolf deaths prompted by removing protections, of which cryptic poaching would comprise the majority, in addition to the hunting deaths.

We estimate a population reduction of at least $27-33 \%$ in one year, which contradicts the expectation by the state wildlife agency that there would be no reduction in the wolf population. Moreover, our estimates are strict minima for actual reductions in the population, so our population estimate is a maximum conceivable under the most conservative assumptions. The reality is probably a greater reduction and a lower population count as of writing.

If the second planned wolf-hunt in November 2021 (SM 1) were cancelled, we predict the state wolf population could rebound in 1-2 years. However, there are preliminary indications from the state Natural Resource Board that another wolf-hunt with a similar or higher quota will be advocated by some on the board (SM 1). Proponents for such point to the 1999 population goal for wolves of 350 individuals in late winter. We have shown that number is a value judgment by a few individuals not a scientifically sound target [51]. Therefore, the adequacy of state regulatory mechanisms seems fragile, for reasons detailed in SM1 for those interested in policy background. The frailty of regulatory mechanisms can be summarized as follows:

1. The intervention of numerous branches of the state government (SM1)

2. A Wisconsin statute which mandates a hunt in the event of federal delisting, rather than granting discretion to the DNR (SM1)

3. Various disparate estimates of the population size, the hunter take, poaching, and resilience that have been espoused by officials and the public (SM1)

In sum, the state wildlife agency (DNR) did not meet its explicit objectives of no change in the wolf population, still being advocated by that agency as of writing (https://dnr.wisconsin.gov/topic/hunt/wolf/index.html accessed 16 April 2021). The facts of 
304 hunters over-shooting the quota by $83 \%$ before the DNR could close zones, of the Natural

305 Resource Board over-ruling the DNR's more cautious permit number, the legislature mandating

306 a hunt, a county court ordering a hunt on very short notice, and an appeals court declining to

307 review that decision (SM1) all speak to problems with different branches intervening to reduce

308 the discretion of the wildlife agency. That loss of discretion by the ostensible expert managers

309 itself raises serious questions about the adequacy of regulatory mechanisms to prevent wolves

310 becoming endangered again. It also leads us to recommend reform of trustee duties in the

311 state and perhaps others with unclear responsibilities and unclear divisions between decision-

312 making and implementation functions.

313

314

315

\section{Conclusions}

For jurisdictions elsewhere, we caution that science may play little role in wolf politics where the animal has become a symbol for political rhetoric and a symbol of cultural divisions [52]. However, science only reveals past, present or future conditions, not what we humans ought to do.

Proponents of wolf-killing argued that the state population goal of 350 wolves demands such swift reductions (SM 1), but evidence suggests that goal is a value judgment by a few individuals that was treated as if it were an output of a scientific model [53]. Moreover, that the model used suffers from scientific flaws, so its assumptions and predictions are dubious [53]. Nevertheless, the goal was reaffirmed in February 2021 (SM 1). Furthermore, the state did not collect wolf carcasses for aging or detection of alpha females by placental scars, as is fairly standard for scientific studies, e.g., [54] - see SM1. This type of scientific information is indispensable for science-based management. Without it, illegal wolf-killing is more difficult to detect, the age and reproductive class of hunter-killed wolves is likely imprecise, and the breeding status and hence reproductive performance for the following year cannot be estimated accurately.

331

332

Likewise, state plans for another hunt raise questions about sustainability. Although one subnational jurisdiction may not predict another, doubts about sustainable wolf-killing and misuse of scientific information have been raised previously for several other governments (see [55] and [56], respectively). Therefore, we find our case is not unique, and provides insights for other jurisdictions. Similar wolf-killing might be replicated elsewhere when subnational jurisdictions in the USA and EU regain authority for controversial predators. Federal governments in both regions should recognize that loosening protections for predators, and perhaps other controversial species, opens the door for antagonists $[4,57]$ to kill large numbers in short periods, legally and illegally. The history of political scapegoating of wolves [56, 58] may repeat itself. Elsewhere, we have shown that the response should not be to allow more wolfkilling under the misguided concept of blood buys goodwill or 'tolerance killing' $[27,28,33,45]$.

Federal decision-makers might consider different classifications that make predators protected non-game, or states should prove themselves capable of reducing poaching to a stringent minimum for a 5-year post-delisting monitoring period. Alternately, federal governments might address upgrades to federal laws regardless of species classifications. Given the importance of 
348 predators in restoring ecosystem health and function [59] and non-anthropocentric wildlife 349 trusteeship $[33,60]$, we also recommend instead that transparent legal standards of

350 trusteeship be used to manage wildlife [61,62], not the vagaries of opaque electoral politics 351 and interest group lobbying [51]. Moreover, our recommendation conforms to global goals for 352 the preservation of nature.

353

354 Acknowledgments

355 UW-Madison supported FSA during his post-doctoral research. 
357

358

359

360

361

362

363

364

365

366

367

368

369

370

371

372

373

374

375

376

377

378

379

380

381

382

383

384

385

386

387

388

389

390

391

392

393

394

395

396

397

398

399

400

\section{References cited}

1. Mech, L.D., The Challenge of Wolf Recovery: An Ongoing Dilemma for State Managers. Wildlife Society News, 2013. 22 March 2013: p. 1-5.

2. Bruskotter, J.T., J.A. Vucetich, K.M. Slagle, R. Berardo, A.S. Singh, and R.S. Wilson, Support for the U.S. Endangered Species Act over time and space: Controversial species do not weaken public support for protective legislation. Conservation Letters, 2018. ;e12595: p. 1-7. https://doi.org/10.1111/conl.12595.

3. Manfredo, M.J., T.L. Teel, A.W. Don Carlos, L. Sullivan, A.D. Bright, A.M. Dietsch, J. Bruskotter, and D. Fulton, The changing sociocultural context of wildlife conservation. Conservation Biology, 2020. 10.1111/cobi.13493.

https://www.ncbi.nlm.nih.gov/pubmed/32128885.

4. Treves, A. and K.A. Martin, Hunters as stewards of wolves in Wisconsin and the Northern Rocky Mountains, USA. Society and Natural Resources, 2011. 24(9): p. 984-994.

5. Chapron, G., P. Kaczensky, J.D.C. Linnell, M. von Arx, D. Huber, H. Andrén, J.V. LópezBao, M. Adamec, F. Álvares, O. Anders, L. Balčiauskas, V. Balys, P. Bedő, F. Bego, J.C. Blanco, U. Breitenmoser, H. Brøseth, L.k. Bufka, R. Bunikyte, P. Ciucci, A. Dutsov, T. Engleder, C. Fuxjäger, C. Groff, K. Holmala, B. Hoxha, Y. Iliopoulos, O. Ionescu, J. Jeremić, K. Jerina, G. Kluth, F. Knauer, I. Kojola, I. Kos, M. Krofel, J. Kubala, S. Kunovac, J. Kusak, M. Kutal, O. Liberg, A. Majić, P. Männil, R. Manz, E. Marboutin, F. Marucco, D. Melovski, K. Mersini, Y. Mertzanis, R.W. Mysłajek, S. Nowak, J. Odden, J. Ozolins, G. Palomero, M. Paunović, J. Persson, H. Potočnik, P.-Y. Quenette, G. Rauer, I. Reinhardt, R. Rigg, A. Ryser, V. Salvatori, T. Skrbinšek, A. Stojanov, J.E. Swenson, L. Szemethy, A. Trajçe, E. Tsingarska-Sedefcheva, M. Váňa, R. Veeroja, P. Wabakken, M. Wölfl, S. Wölfl, F. Zimmermann, D. Zlatanova, and L. Boitani, Recovery of large carnivores in Europe's modern human-dominated landscapes. Science, 2014. 346(6216): p. 1517.

6. Dressel, S., C. Sandström, and G. Ericsson, A meta-analysis of studies on attitudes toward bears and wolves across Europe 1976-2012. Conservation Biology, 2014. 29(2): p. 568-574.

7. NCEAS, Review of Proposed Rule Regarding Status of the Wolf Under the Endangered Species Act. 2014, National Center for Ecological Analysis and Synthesis.

8. Atkins, Summary Report of Independent Peer Reviews for the U.S. Fish \& Wildlife Service Gray Wolf Delisting Review. 2019, Atkins: https://www.fws.gov/endangered/esalibrary/pdf/Final\%20Gray\%20Wolf\%20Peer\%20Review\%20Summary\%20Report 053119 .pdf. https://www.fws.gov/endangered/esa-

library/pdf/Final\%20Gray\%20Wolf\%20Peer\%20Review\%20Summary\%20Report 053119 .pdf.

9. USFWS, D., Endangered and Threatened Wildlife and Plants; Removing the Gray Wolf (Canis lupus) From the List of Endangered and Threatened Wildlife (Final rule). Federal Register, 2020. 85(213): p. 69778-69895 https://www.govinfo.gov/content/pkg/FR2020-11-03/pdf/202024171.pdf?utm campaign=subscription+mailing+list\&utm source=federalregister.gov \& utm medium=email. 
401 10. Zellmer, S.B., S.J. Panarella, and O.F. Wood, Species Conservation \& Recovery Through

402

403

404

405

406

407

408

409

410

411

412

413

414

415

416

417

418

419

420

421

422

423

424

425

426

427

428

429

430

431

432

433

434

435

436

437

438

439

440

441

442

443

444 Adequate Regulatory Mechanisms Harvard Environmental LAw Review, 2020. 44(2): p. 367-417. https://scholarship.law.umt.edu/faculty barjournals/152.

11. Erickson, A.B., Grizzly bear recovery, whitebark pine, and adequate regulatory mechanisms under the endangered species act. Environmental Law, 2012. 42(3): p. 943976.

12. Treves, A., K.A. Artelle, C.T. Darimont, and D.R. Parsons, Mismeasured mortality: correcting estimates of wolf poaching in the United States. Journal of Mammalogy, 2017. 98(5): p. 1256-1264. I:10.1093/jmammal/gyx052

https://doi.org/10.1093/jmammal/gyx052.

13. Boitani, L., Ecological and cultural diversities in the evolution of wolf-human relationships, in Ecology and conservation of wolves in a changing world, L.N. Carbyn, S.H. Fritts, and D.R. Seip, Editors. 1995, Canadian Circumpolar Institute: Edmonton, Alberta, Canada. p. 3-11.

14. Anderson, J., Lessons from Wisconsin's controversial wolf hunt, in Minneapolis Star Tribune. 2021. https://www.startribune.com/lessons-from-wisconsin-s-controversialwolf-hunt/600031216/.

15. Adams, L.G., R.O. Stephenson, B.W. Dale, R.T. Ahgook, and D.J. Demma, Population dynamics and harvest characteristics of wolves in the Central Brooks Range, Alaska Wildlife Monographs, 2008. 170: p. 1-25.

16. Fuller, T.K., L.D. Mech, and J.F. Cochrane, Wolf population dynamics, in Wolves: Behavior, ecology, and conservation, L.D. Mech and L. Boitani, Editors. 2003, University of Chicago Press: Chicago. p. 161-191.

17. Creel, S. and J.J. Rotella, Meta-analysis of relationships between human offtake, total mortality and population dynamics of gray wolves (Canis lupus). PLoS ONE, 2010. 5(9): $p$. 1-7.

18. Vucetich, J.A., Appendix: The influence of anthropogenic mortality on wolf population dynamics with special reference to Creel and Rotella (2010) and Gude et al. (2011) in the Final peer review of four documents amending and clarifying the Wyoming gray wolf management plan. Federal Register, 2012. 50: p. 78-95.

https://www.federalregister.gov/documents/2012/05/01/2012-10407/endangeredand-threatened-wildlife-and-plants-removal-of-the-gray-wolf-in-wyoming-from-thefederal.

19. Gude, J.A., M.S. Mitchell, R.E. Russell, C.A. Sime, E.E. Bangs, L.D. Mech, and R.R. Ream, Wolf population dynamics in the U.S. Northern Rocky Mountains are affected by recruitment and human-caused mortality. Journal of Wildlife Management, 2012. 76(1): p. 108-118.

20. Natural Resources Board, Adoption of Board Order WM-09012(E) relating to wolf hunting and trapping regulations, establishment of a depredation program, and approval of a harvest quota and permit level, N.R. Board, Editor. 2012, Wisconsin Department of Natural Resources: Madison, WI. p. 58.

21. Natural Resources Board, Request approval of a wolf harvest quota and number of licenses to issue for the 2014-2015 wolf hunting and trapping season. 2014, Department of Natural Resources. : Madison, Wisconsin p. 10. 
445

446

447

448

449

450

451

452

453

454

455

456

457

458

459

460

461

462

463

464

465

466

467

468

469

470

471

472

473

474

475

476

477

478

479

480

481

482

483

484

485

486

487

22. Natural Resources Board, Request that the Board take action to consider approval of a quota for a February 2021 wolf hunt in accordance with the circuit court order issued on February 11, 2021 in Hunter Nation et al. v. WDNR, et al, Civ. No. 2021-CV-31 (Jefferson County). 2021, Department of Natural Resources. : Madison, Wisconsin p. 3. https://widnr.widen.net/view/pdf/sbdtbr1v2w/2021-02-2A-Special-meeting-wolfquota.pdf?t.download=true\&u=ulxjan.

23. Natural Resources Board, 15 February 2021 Special Meeting, N.R. Board, Editor. 2021. p. $37 \mathrm{~min}$, transcript and video available from authors. https://dnrmedia.wi.gov/main/Play/ccb5cf0361c5471e9cbc7c7a898cfc741d?catalog=9d a0bb432fd448a69d86756192a62f1721.

24. Chapron, G. and A. Treves, Blood does not buy goodwill: allowing culling increases poaching of a large carnivore. Proceedings of the Royal Society B, 2016. 283(1830): p. 20152939. http://dx.doi.org/10.1098/rspb.2015.2939

25. Chapron, G. and A. Treves, Correction to 'Blood does not buy goodwill: allowing culling increases poaching of a large carnivore'. Proceedings of the Royal Society B, 2016. Volume 283(1845): p. 20162577.

26. Chapron, G. and A. Treves, Reply to comment by Pepin et al. 2017. Proceedings of the Royal Society B, 2017. 2016257(1851): p. 20162571.

http://dx.doi.org/10.1098/rspb.2015.2939

27. Chapron, G. and A. Treves, Reply to comments by Olson et al. 2017 and Stien 2017. Proceedings of the Royal Society B, 2017. 284(1867): p. 20171743.

28. Santiago-Ávila, F.J., R.J. Chappell, and A. Treves, Liberalizing the killing of endangered wolves was associated with more disappearances of collared individuals in Wisconsin, USA. Scientific Reports, 2020. 10: p. 13881. /10.1038. I https://doi.org/10.1038/s41598020-70837-x.

29. DNR, Presentation by J. Price Tack to Wolf Harvest Committee 8 Aprl 2021, D.o.N. Resources, Editor. 2021: Madison, WI.

30. DNR, NRB Wolf Information request: Agenda Item 2A-January 22, 2021 Special Meeting, D.o.N. Resources, Editor. 2021: Madison, WI. https://widnr.widen.net/s/vh58xn8lfr/2021-01-2a-additional-information.

31. Wydeven, A.P., J. Wiedenhoeft, R.N. Schultz, R.P. Thiel, R.R. Jurewicz, B. Kohn, and T.R. Van Deelen, History, population growth and management of wolves in Wisconsin, in Recovery of Gray Wolves in the Great Lakes Region of the United States: an Endangered Species Success Story, A.P. Wydeven, T.R. Van Deelen, and E.J. Heske, Editors. 2009, Springer: New York. p. 87-106.

32. Liberg, O., G. Chapron, P. Wabakken, H.C. Pedersen, N.T. Hobbs, and H. Sand, Shoot, shovel and shut up: cryptic poaching slows restoration of a large carnivore in Europe. Proceedings of the Royal Society of London Series B, 2012. 270: p. 91-98.

33. Louchouarn, N.X., F.J. Santiago-Ávila, D.R. Parsons, and A. Treves, Evaluating how lethal management affects poaching of Mexican wolves Open Science, 2021.8 (registered report): p. 200330. https://doi.org/10.1098/rsos.200330.

34. Agan, S.W., A. Treves, and L. Willey, Wild red wolf Canis rufus poaching risk. bioRxiv, 2020. https://doi.org/10.1101/2020.12.08.416032. 
488

489

490

491

492

493

494

495

496

497

498

499

500

501

502

503

504

505

506

507

508

509

510

511

512

513

514

515

516

517

518

519

520

521

522

523

524

525

526

527

528

529

530

531

35. Treves, A., J.A. Langenberg, J.V. López-Bao, and M.F. Rabenhorst, Gray wolf mortality patterns in Wisconsin from 1979 to 2012. Journal of Mammalogy, 2017. 98(1): p. 17-32. DOI:10.1093/jmammal/gyw145.

36. Olson, E.R., J.L. Stenglein, Victoria Shelley, Adena R. Rissman, Christine Browne-Nuñez, Zachary Voyles, A.P. Wydeven, and T.V. Deelen, Pendulum swings in wolf management led to conflict, illegal kills, and a legislated wolf hunt. Conservation Letters, 2015. 8(5): p. 351-360.

37. Stenglein, J.L., J. Zhu, M.K. Clayton, and T.R. Van Deelen, Are the numbers adding up? Exploiting discrepancies among complementary population models. Ecology and Evolution, 2015. 5(2): p. 368-376.

38. Stenglein, J.L., A.P. Wydeven, and T.R. Van Deelen, Compensatory mortality in a recovering top carnivore: wolves in Wisconsin, USA (1979-2013). Oecologia, 2018. 187(1): p. 99-111. https://doi.org/10.1007/s00442-018-4132-4.

39. Stien, A., Blood may buy goodwill - no evidence for a positive relationship between legal culling and poaching in Wisconsin. Proceedings of the Royal Society B, 2017. 284: p. 20170267. http://dx.doi.org/10.1098/rspb.2017.0267.

40. Pepin, K., S. Kay, and A. Davis, Comment on: "Blood does not buy goodwill: allowing culling increases poaching of a large carnivore". Proceedings of the Royal Society B, 2017. 284(1851): p. e20161459.

41. Olson, E.R., S. Crimmins, D.E. Beyer, D. MacNulty, B. Patterson, B. Rudolph, A. Wydeven, and T.R. Van Deelen, Flawed analysis and unconvincing interpretation: a comment on Chapron and Treves 2016. Proceedings of the Royal Society of London B, 2017. 284(1867): p. 20170273.

42. Browne-Nuñez, C., A. Treves, D. Macfarland, Z. Voyles, and C. Turng, Tolerance of wolves in Wisconsin: A mixed-methods examination of policy effects on attitudes and behavioral inclinations. Biological Conservation, 2015. 189: p. 59-71.

43. Hogberg, J., A. Treves, B. Shaw, and L. Naughton-Treves, Changes in attitudes toward wolves before and after an inaugural public hunting and trapping season: early evidence from Wisconsin's wolf range. Environmental Conservation, 2015. 43(1): p. 45-55.

44. Treves, A., L. Naughton-Treves, and V.S. Shelley, Longitudinal analysis of attitudes toward wolves. Conservation Biology, 2013. 27: p. 315-323.

45. Treves, A. and J.T. Bruskotter, Tolerance for predatory wildlife. Science, 2014. 344(6183): p. 476-477.

46. Liberg, O., J. Suutarinen, M. Åkesson, H. Andrén, P. Wabakken, C. Wikenros, and H. Sand, Poaching-related disappearance rate of wolves in Sweden was positively related to population size and negatively to legal culling. Biological Conservation, 2020. 243. 10.1016/j.biocon.2020.108456.

47. Treves, A., N.X. Louchouarn, and F. Santiago-Ávila, Modelling concerns confound evaluations of legal wolf-killing. Biological Conservation, 2020. ttps://doi.org/10.1016/j.biocon.2020.108643: p. 108643. 10.1016/j.biocon.2020.108643. ttps://doi.org/10.1016/j.biocon.2020.108643.

48. Schmidt, J.H., D.S. Johnson, M.S. Lindberg, and L.G. Adams, Estimating demographic parameters using a combination of known-fate and open $N$-mixture models. Ecology, 2015. 56(10): p. 2583-2589. http://dx.doi.org/10.1890/15-0385.1.

Peer] reviewing PDF | (2021:03:59550:1:1:NEW 28 Apr 2021) 
532 49. Persson, J., G.R. Rauset, and G. Chapron, Paying for an endangered predator leads to

533

534

535

536

537

538

539

540

541

542

543

544

545

546

547

548

549

550

551

552

553

554

555

556

557

558

559

560

561

562

563

564

565

566

567

568

569

570

571

572

573

574

575 population recovery. Conservation Letters, 2017. 8(5): p. 345-350.

50. Fuller, T.K., Population dynamics of wolves in north central Minnesota. Wildlife Monographs, 1989. 105: p. 3-41.

51. Treves, A., G. Chapron, J.V. López-Bao, C. Shoemaker, A. Goeckner, and J.T. Bruskotter, Predators and the public trust. Biological Reviews, 2017. 92: p. 248-270.

52. Nie, M., Beyond Wolves: The Politics of Wolf Recovery and Management. 2003, Minneapolis, MN, USA: University of Minnesota Press. 253.

53. Treves, A., P.C. Paquet, K.A. Artelle, A.M. Cornman, M. Krofel, and C.T. Darimont, Transparency about values and assertions of fact in natural resource management. Frontiers in Conservation Science: Human-Wildlife Dynamics, 2021. 2: p. 631998. DOI: 10.3389/fcosc.2021.631998.

54. Stark, D. and J. Erb, 2012 Minnesota wolf season report. 2013, Minnesota Department of Natural Resources: Grand Rapids, MN. http://files.dnr.state.mn.us/fish wildlife/wildlife/wolves/2013/wolfseasoninfo 2012.pd f.

55. Creel, S., M. Becker, D. Christianson, E. Dröge, N. Hammerschlag, M.W. Hayward, K.U. Karanth, A.J. Loveridge, D. Macdonald, W. Matandiko, J. M'soka, D. Murray, E. Rosenblatt, and P. Schuette, Questionable policy for large carnivore hunting. Science, 2015. 350(6267): p. 1473-1475.

56. Chapron, G., J.V. López Bao, P. Kjellander, and J. Karlsson, Misuse of Scientific Data in Wolf Policy. Science, 2013. 339: p. 1521.

57. Brown, M. and I. Samuels, US states look to step up wolf kills, pushed by Republicans, in Associated Press. 2021: https://apnews.com/article/donald-trump-wildlife-animalslakes-billings-5eda7213f2cbec6c3d46897e74dddf80. https://apnews.com/article/donald-trump-wildlife-animals-lakes-billings5eda7213f2cbec6c3d46897e74dddf80.

58. Chapron, G. and J. Lopez-Bao, Conserving Carnivores: Politics in Play. Science, 2014. 343(14): p. 1199-1200.

59. Estes, J.A., J. Terborgh, J.S. Brashares, M.E. Power, J. Berger, W.J. Bond, S.R. Carpenter, T.E. Essington, R.D. Holt, J.B.C. Jackson, R.J. Marquis, L. Oksanen, T. Oksanen, R.T. Paine, E.K. Pikitch, W.J. Ripple, S.A. Sandin, M. Scheffer, T.W. Schoener, J.B. Shurin, A.R.E. Sinclair, M.E. Soulé, R. Virtanen, and D.A. Wardle, Trophic Downgrading of Planet Earth. Science, 2011. 333(6040): p. 301-306.

60. Santiago-Avila, F.J., W.S. Lynn, and A. Treves, Inappropriate consideration of animal interests in predator management: Towards a comprehensive moral code, in Large Carnivore Conservation and Management: Human Dimensions and Governance, T. Hovardos, Editor. 2018, Taylor \& Francis: New York. p. 227-251.

61. Bruskotter, J.T., S. Enzler, and A. Treves, Rescuing wolves from politics: wildlife as a public trust resource. Science, 2011. 333(6051): p. 1828-1829.

62. Treves, A., K.A. Artelle, C.T. Darimont, W.S. Lynn, P.C. Paquet, F.J. Santiago-Avila, R. Shaw, and M.C. Wood, Intergenerational equity can help to prevent climate change and extinction. Nature Ecology \& Evolution, 2018. 2: p. 204-207.

https://doi.org/10.1038/s41559-018-0465-y. 


\section{Table $\mathbf{1}$ (on next page)}

Table 1

Population and extra mortality estimation in scenario MODERATE that assumes annual change $-2.2 \%$ by Apr 2021 
1

2 Table 1. Population and extra mortality estimation in scenario $\mathrm{HIGH}$ that assumes annual

3 growth $+3.8 \%$ by Apr 2021

\begin{tabular}{|c|c|c|c|}
\hline \multirow{2}{*}{$\begin{array}{l}\text { TIMELINE OF WOLF } \\
\text { POPULATION CHANGES }\end{array}$} & \multirow{2}{*}{$\mathbf{N}$} & \multicolumn{2}{|c|}{ INDIVIDUALS DEAD AND DISAPPEARED } \\
\hline & & $\begin{array}{c}\text { Additional, due } \\
\text { to reduced ESA } \\
\text { protections* }\end{array}$ & Notes \\
\hline $\begin{array}{l}15 \text { April } 2020 \text { in } 256 \\
\text { packs, Day } 0\end{array}$ & 1034 & & $\begin{array}{l}\text { We assume wolves begin } \\
\text { monitoring on this date }\end{array}$ \\
\hline $\begin{array}{l}\text { Expected by } 2 \text { Nov } \\
\text { 2020, Day } 201 \text { - } \\
\text { REDUCED PROTECTION } \\
\text { PERIOD BEGINS ON } 3 \\
\text { NOV } 2020\end{array}$ & 1073 & 97 & $\begin{array}{l}\text { Nov 3-Feb } 21 \text { (Days } 202-312,111 \\
\text { day interval): Liberalized wolf- } \\
\text { killing period cumulative incidence } \\
\text { as a relative increment of }+0.09 \text { for } \\
\text { all endpoints relative to baseline of } \\
\text { strict ESA protection }\end{array}$ \\
\hline $\begin{array}{l}\text { Expected by } 24 \text { Feb } \\
\text { 2021, Day } 315 \text { - END OF } \\
\text { WOLF-HUNT }\end{array}$ & 759 & 218 & $\begin{array}{l}\text { Legal kills during wolf-hunt Feb 22- } \\
24 \text { ( } 3 \text { days) }\end{array}$ \\
\hline $\begin{array}{l}\text { Expected by } 15 \text { Apr } \\
\text { 2021, Day } 365\end{array}$ & 751 & 8 & $\begin{array}{l}\text { Feb } 22-\text { Apr } 14 \text { (Days } 313-365,51 \\
\text { day interval): Liberalized wolf- } \\
\text { killing period cumulative incidence } \\
\text { as a relative increment of }+0.01 \text { for } \\
\text { all endpoints relative to baseline of } \\
\text { strict ESA protection }\end{array}$ \\
\hline
\end{tabular}

* Source for all cumulative incidences is [15]. 


\section{Table 2 (on next page)}

Table 2

Population and extra mortality estimation in scenario HIGH that assumes annual growth $+3.8 \%$ by Apr 2021 
1

2 Table 2. Population and extra mortality estimation in scenario MODERATE that assumes annual

3 change $-2.2 \%$ by Apr 2021

\begin{tabular}{|c|c|c|c|}
\hline \multirow{2}{*}{$\begin{array}{l}\text { TIMELINE OF WOLF } \\
\text { POPULATION CHANGES }\end{array}$} & \multirow{2}{*}{$\mathbf{N}$} & \multicolumn{2}{|c|}{ INDIVIDUALS DEAD AND DISAPPEARED } \\
\hline & & $\begin{array}{c}\text { Additional, due } \\
\text { to reduced ESA } \\
\text { protections* }\end{array}$ & Notes \\
\hline $\begin{array}{l}15 \text { April } 2020 \text { in } 256 \\
\text { packs, Day } 0\end{array}$ & 1034 & & $\begin{array}{l}\text { We assume wolves begin } \\
\text { monitoring on this date }\end{array}$ \\
\hline $\begin{array}{l}\text { Expected by } 2 \text { Nov } \\
\text { 2020, Day } 201 \text { - } \\
\text { REDUCED PROTECTION } \\
\text { PERIOD BEGINS ON } 3 \\
\text { NOV } 2020\end{array}$ & 1011 & 91 & $\begin{array}{l}\text { Nov 3-Feb } 21 \text { (Days } 202-312,111 \\
\text { day interval): Liberalized wolf- } \\
\text { killing period cumulative incidence } \\
\text { as a relative increment of }+0.09 \text { for } \\
\text { all endpoints relative to baseline of } \\
\text { strict ESA protection }\end{array}$ \\
\hline $\begin{array}{l}\text { Expected by } 24 \text { Feb } \\
\text { 2021, Day } 315 \text { - END OF } \\
\text { WOLF-HUNT }\end{array}$ & 702 & 218 & $\begin{array}{l}\text { Legal kills during wolf-hunt Feb } 22- \\
24 \text { ( } 3 \text { days) }\end{array}$ \\
\hline $\begin{array}{l}\text { Expected by } 15 \text { Apr } \\
2021 \text {, Day } 365\end{array}$ & 695 & 7 & $\begin{array}{l}\text { Feb } 22-\text { Apr } 14 \text { (Days } 313-365,51 \\
\text { day interval): Liberalized wolf- } \\
\text { killing period cumulative incidence } \\
\text { as a relative increment of }+0.01 \text { for } \\
\text { all endpoints relative to baseline of } \\
\text { strict ESA protection }\end{array}$ \\
\hline
\end{tabular}

* Source for all cumulative incidences is [15]. 


\section{Figure 1}

fig 1

Cumulative Incidence of endpoints by protection period. Cumulative incidence functions (CIFs) for 499 monitored, adult wolves in Wisconsin during two policy periods (gray: reduced ESA protections; black: full ESA protections) for all deaths and disappearances (Panel A: $n=499$ ), and disappearances only (Panel $B: n=243$ ) from 1979-2012. Coordinates $(x, y)$ represent the cumulative incidence or proportion of monitored wolves experiencing an endpoint (y-axis); showing all deaths in $(A)$ or all disappearances in $(B)$, over time (x-axis) in days. Time zero is set to 16 April 2020, a conservative step because death or disappearance increases with time, by definition. CIFs modeled with semi-parametric Fine-Gray models [27]. The first period of 201 days runs from 15 April 2020 to 3 November 2020 when delisting was announced in the Federal Register [9] and the period of reduced ESA protection began. Day 312 marks the start of the Wisconsin wolf-hunt on 22 Feb 2021, and day 365 marks the end of the wolf-year on 14 April 2021. Finally, day 566 marks the approximate start date of the putative, next wolf-hunt, to illustrate further increases in the CIFs of mortalities and disappearances. We used the increment between the period of full ESA protection (black markers) to the corresponding value on the upper curve of reduced ESA protection (gray markers) to estimate the additional wolves deducted from the population by any endpoint (A) or LTF; (B) which we interpret as cryptic poaching as explained in Main text. 


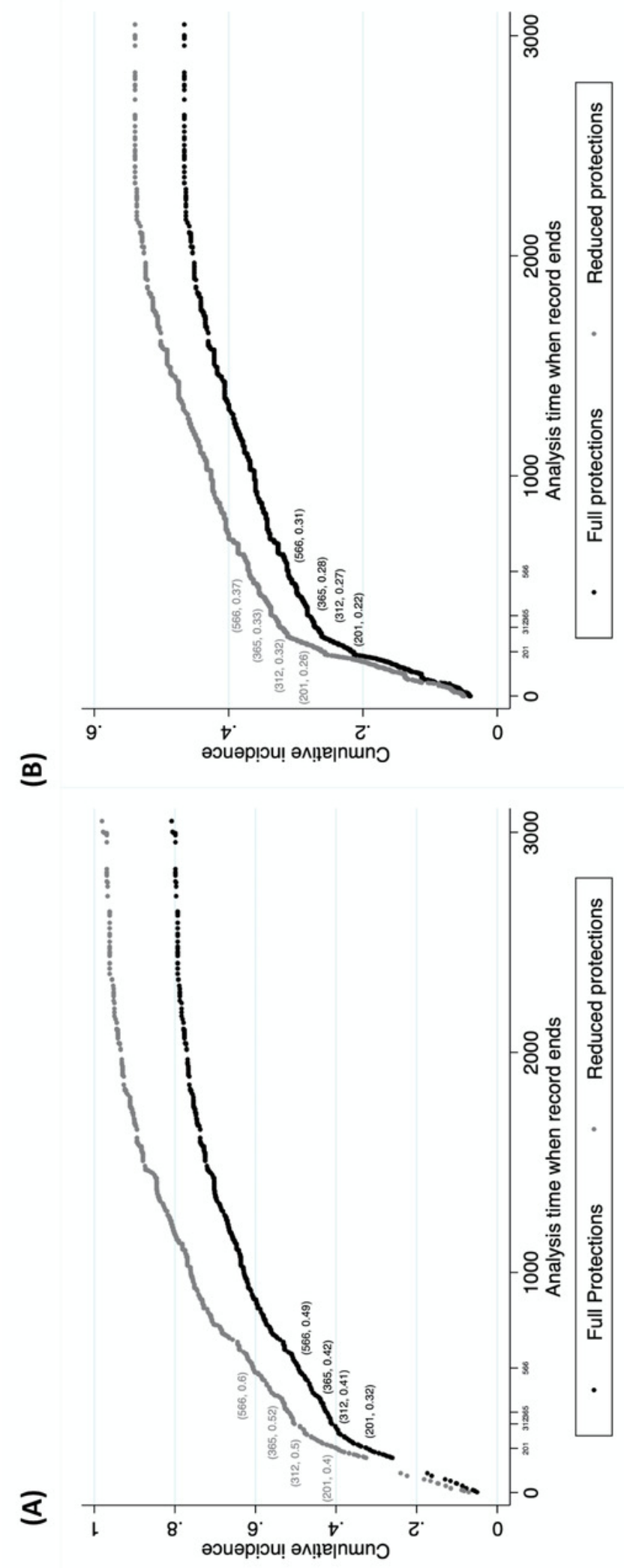

